\title{
Sisu Manthalawa: Guiding Students towards a Better Future
}

\author{
R. S. Thelis \\ Faculty of Computing, \\ Sri Lanka Institute of \\ Information Technology, \\ Colombo 03, \\ Sri Lanka
}

\author{
K. T. Jayatunge \\ Faculty of Computing, \\ Sri Lanka Institute of \\ Information Technology, \\ Colombo 03, \\ Sri Lanka
}

\author{
K. A. A. D. Kumarapeli \\ Faculty of Computing, \\ Sri Lanka Institute of \\ Information Technology, \\ Colombo 03, \\ Sri Lanka
}

\author{
C. A. Senadheera \\ Faculty of Computing, \\ Sri Lanka Institute of \\ Information Technology, \\ Colombo 03, \\ Sri Lanka
}

\author{
D. Dhammearatchi \\ Faculty of Computing \\ SLIIT Computing (Pvt.) Ltd., \\ Colombo 03 \\ Sri Lanka
}

\begin{abstract}
Learning one's own strengths and weaknesses is essential when making important life decisions; especially for students that are obliged to make decisions about what path they are to persuade leading them to a carrier path without regret. Today most of the students do not have a proper understanding of their own talents, abilities or how they can accomplish their future goals. The system mentioned in this research paper provides a solution by helping grade 10 and 11 local students to learn about their own strengths and weaknesses thus guiding them when making important decisions about what paths to follow in the future and what aspect they need to improve on. Students' past performances, logical thinking and other attributes were taken into consideration to provide an accurate and comprehensible output depicting their weaknesses and strengths. Moreover, the output was analysed and used to aid teachers when dividing student groups inside the classroom for cooperative group activities. An intelligent system driven by algorithms to support logical and cooperative grouping strategies that uses statistical analysis and output analysis along with an online quiz for students to learn their logical thinking skills were used to produce the expected output. Information about extracurricular activities were collected from a selected group of 50 students using a questionnaire that had being analysed by the research group. Patterns of students' scoring were analysed to predict the score the same student would gain in the future using data mining methods and tools. Sisu Manthalawa is a web application that can help the local students to make decisions thus helping them stride towards a better future.
\end{abstract}

\section{Keywords}

Cooperative group activities, data mining, grouping strategies, intelligent system, logical thinking, making decisions, online quiz, strengths, weaknesses

\section{INTRODUCTION}

Most of the students nowadays barely have a say in what studies they are choosing to follow, which has become a major problem. Many employees are having doubts about the career paths they have chosen to follow and they spend most of their time studying what they desire, while 'wasting' their time on a job they would rather not do.

The research was conducted to help the students who struggle when figuring out their weaknesses and aptitudes. A web based system was developed to analyse students' exam results, assessment marks and extracurricular activities to measure their performance. Through learning their weaknesses using this output, students can spend more time working on eliminating their weaknesses or refining their skills further, allowing them to perform better next time. Another common problem that arises within a classroom is teachers failing to group among students hence their talents altogether cover all aspects needed for a group (Leadership, Mathematical, technical skills etc.). Looking at each student's individual skills provided by the system outputs, it is made easier for teachers to group students efficiently. The research team used technologies such as data mining algorithms, statistical analysis and logical thinking patterns to build the intelligent system. The system prioritized the local students of Sri Lanka in grade ten, eleven and students who are willing to start $\mathrm{A} / \mathrm{L}$ (Advanced Level). The objectives of this research were as follows; a) to measure student performance to help them figure out their weaknesses and strengths, b) to suggest a suitable $\mathrm{A} / \mathrm{L}$ stream for each student, c) to group students inside a classroom efficiently.

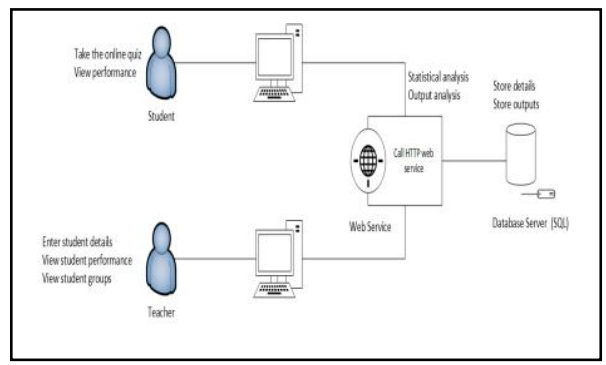

Figure 1. Architecture Diagram 
The Figure 1 above illustrates the architecture diagram the end users are students and teachers. First teacher has to send a report about her/his student details such as name, class identity number, school etc. to the admin. If a student wishes to use this web site, student can request for an account to be created in the web system. The admin compares details which student submitted with teachers' report. If the details match, admin creates an account with necessary access levels for the students and the teacher. The teachers enter student details to the database through the internet and web server. Using the data in database, current performance of the students will be measured. Data mining algorithms predict a suitable path for after ordinary level students according to $\mathrm{O} / \mathrm{L}$ results. The system also predict $\mathrm{A} / \mathrm{L}$ results which can be perform by student in future, this option is only for teachers. System uses the performance output to group students.

\section{BACKGROUND 2.1 Introduction}

During the last 10-15 years, a large number of research projects have focused on developing educational based systems to reach the higher aspects of educational needs. Significantly many researches have studied on measuring student performance and student grouping up to some extent. Although most researches have issues regarding lack of data to mining and proper way to cover students' performance in all aspects. This project proposes to solve the existing problems.

\subsection{Student Grouping}

Since past, the criteria for in-classroom grouping has been an issue. Mostly it was done by manually as for the students liking. In 2005. The results obtained showed significant improvements, both qualitative and quantitative, in the environment where dynamic grouping was used. Moreover, the criteria for group composition that produce different social interaction outcomes were identified [4]. In 2007 according Barbara A. Oakley et al. assigning work to student teams can lead to learning benefits and student satisfaction, provided that the instructor pays attention to how the teams and the assignments are set up [2]. In 2008 comparing different data mining methods and techniques for classifying students based on their Moodle usage data and the final marks obtained in their respective courses Cristóbal Romero et al. developed a specific mining tool for making the configuration and execution of data mining techniques easier to discover potential student groups with similar characteristics. Then in 2013 it found that cultural differences between the two countries, with respect to the collectivism- individualisms, power distance, and uncertainty avoidance dimensions, were one of the main factors that influenced team satisfaction according to Rami M. Zeitun et al. [3], [13]. Interpersonal incompatibilities between team members can develop or the team members can have divergent opinions about the achievement of their tasks. However some conflicts, if moderate, can be functional and can contribute positively to the performance [14].

\subsection{Student Performance}

Although student achievement is highly influenced by past evaluations, an explanatory analysis has shown that there are also other relevant features. As a direct outcome of this research, more efficient student prediction tools can be developed, improving the quality of education and enhancing school resource management [15]. In 2013 V. Vanno et al. provide empirical evidence on the relationships between academic performance, perceived group PsyCap(Psychological Capital), and individual PsyCap of Thai undergraduate students. [11]. According to M. Richardson et al. GPA highlights the wealth of theoretical elaboration and empirical testing that has been devoted to understanding why some undergraduates perform better than others [10]. M. Gogaa et al aimed at designing a framework of intelligent recommender system, based on background factors, which can predict students' first year academic performance and recommend necessary actions for improvement [1].

\subsection{Decision Making}

Decision making has become a vital component in order to maintain the competitiveness. J. M. Cubillo et al. propose a theoretical model that integrates the different groups of factors which influence the decision making process of international students, analysing different dimensions of this process and explaining those factors which determine students' choice [7]. M. J. Murphy et al. combined cross sectional and longitudinal approaches to the analysis of student performance, in SSC (Secondary School Certificate), and in standard-set examinations throughout the curriculum [6].

\subsection{Analysis of Student Mental State and Logical Thinking Capabilities}

Students are now taught in larger groups, which can make it more difficult to make friends and develop a sense of belonging. Using paper questionnaires was the only way that data could be collected at entry to UK Royal College of Psychiatrists as students had not received access to the university email at this point. All the other samples completed an electronic online questionnaire. Ann Macaskill et al. has found that a cross-sectional design was appropriate for this study as it is an exploratory descriptive study [17]. However, many of these students had recently experienced significant levels of concern with various problem areas, including anxiety, depression, relationships, and eating [18]

\subsection{Research Gap}

The literature survey indicates many researches that covers the in-classroom grouping issues which uses Collaborative environments, Online reports, assignment as methodologies [4],[2].also some systems used advanced data mining methodologies [3],[13],[14].then to measure the student's performance many researches have used systematic approaches based on student GPA [10], [11]. For the good predictive accuracy there were few researches which used decision tree algorithms and data mining [8], [1] and [15]. The impact of extracurricular activities to the student studies performance were vital to making an own method to calculate extracurricular performance according to the most effective factors in this implemented system [5] and [9]. It investigated that the development of conditional reasoning skills in undergraduates taking a course in logic. Overall, suggest that studying formal logic improves student's ability to deal with conditional statements, but only if they have had some experience with

Logic previously.so as a result there were many researchers conducted to basically analyse the student's mental strength with the aid of surveys and data mining 
[17], [18]. Lack of resources for data mining, practical issues regarding having questioners in an effective way from a manual system, lack of data and complex algorithms were the major drawbacks as far as these research papers concern. As education is known to be the most important factors to be competitive in the modern world it has occurred a great need of a system which combines student performance measuring, logical thinking and grouping together. "Sisu Manthalawa" is a system that uses algorithms, statistical analysis, logical thinking facts and an intelligent system to measure student's current performances also that uses data mining to predict student's future decisions and to identifying effective student grouping criteria's which was built to overcome the issues of existing researches.

\section{METHODOLOGY}

The prototype methodology was used to achieve the project goals. Analysis, Designing and Implementation phases were executed concurrently and iterated until the project reached all the objectives and the users were satisfied with a final prototype. First prototype was built with minimal amount of features and the rest of the features were added to each prototype produced.

\subsection{Requirement Gathering}

During the requirement phase, raw data of approximately 2500 students from the school Nik/Sri Sumangala Vidyalaya, Wariyapola and $\mathrm{Ch} /$ Dhammissara Madya Maha Vidyalaya, Nattandiya were extracted to be used for data mining. These data contains the assessment marks, O/L and $\mathrm{A} / \mathrm{L}$ results of the students. The stratified sampling method was used to prepare a questionnaire to gather information about $\mathrm{O} / \mathrm{L}$ and $\mathrm{A} / \mathrm{L}$ results, extracurricular activities and about the correlation between extracurricular activities and studies of students. 50 individuals who have already completed the $\mathrm{A} / \mathrm{L}$ examination were chosen to participate for the online questionnaire. A psychiatrist was interviewed to learn about the mental state and the mindset of a student. Due to the unstable nature of a mentality of a growing child of age 15-16, the system functions were deviated to measure the logical thinking aspect of a student.

\subsection{Measuring Performance}

Based on the literature reviewed, the variables: leadership skills, overall studies, extracurricular activities and logical thinking were considered to measure the students' performance standards. Several algorithms were used to calculate these variables for each student. 6 main subjects were considered when measuring the overall studies. Following equation (1) was used.

$$
\mathrm{S}=\underline{(\mathrm{M} * \mathrm{FR})}
$$

$\mathrm{N}$

$\mathrm{N}$ - Number of subjects participated

FR - Subject Fail Rate

M - Subject marks

When measuring the extracurricular activity performance, scores were given if ranks were achieved. A default score was given for the students who have participated for any activity. A leadership score was given if the student held a position in the activity teams. 50 Questions were gathered to measure the logical thinking capabilities of students
Students are prompted to answer random questions through the online Quiz.

\subsection{Grouping Students for Cooperative Learning}

Measured performance level and leadership skills of each student were taken into consideration when grouping students for classroom collaborative activities. A group created according to Doctor Kagan Spencer's cooperative activity grouping theory consists of a student with good leadership skills, a student that performs well in the selected subject, an average student and a weak student to increase the efficiency of cooperative activities.

\subsection{Implementation}

The collected data were mined using decision tree algorithm to predict the suitable $\mathrm{A} / \mathrm{L}$ stream for a student to follow and the expected $\mathrm{A} / \mathrm{L}$ results of the student. Term test results and assessment results were analysed to output a prediction of $\mathrm{O} / \mathrm{L}$ results of students for the teacher to view. The students are warned about the areas of studies they have to focus on while viewing the performance level using SQL Queries. Reference books are also suggested to help them improve in the identified module.

Following tools were used to implement the 'Sisu Manthalawa' Web System.

- $\quad$ Microsoft Visual Studio - IDE

- Dreamweaver CS5.5 - Web page designing

- $\quad$ SQL Server Management Studio - Database managing

- SQL Server Business Intelligence Development Studio - Data mining

- Google Chrome - Web browser

The top-down integration method was used to integrate the final system. System was tested during each phase and after the implementation.

\section{RESULTS AND DISCUSSION}

'Sisu Manthalawa' was developed to help students to improve and balance their academic skills and extracurricular activities depending on their term test results, assignment marks and extra-curricular activity details. Application creates a graph to show results. To divide students into groups based on their subjects by using a special algorithm. The system measures student's logical thinking power by giving an online quizzes. System gives a suggestion to each student that which $\mathrm{A} / \mathrm{L}$ subject stream they should follow based on their $\mathrm{O} / \mathrm{L}$ results and the system is able to predict a student's $\mathrm{O} / \mathrm{L}$ or $\mathrm{A} / \mathrm{L}$ results based on their previous achievements. And teachers are able to view them. 


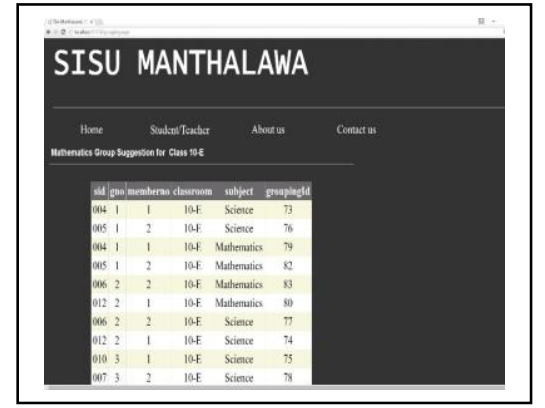

Figure 2. Grouping output

As shown in figure 2, once the Teacher selects the Classroom and the subject the student groups will be displayed on a specifying the group number and the member number of each student.

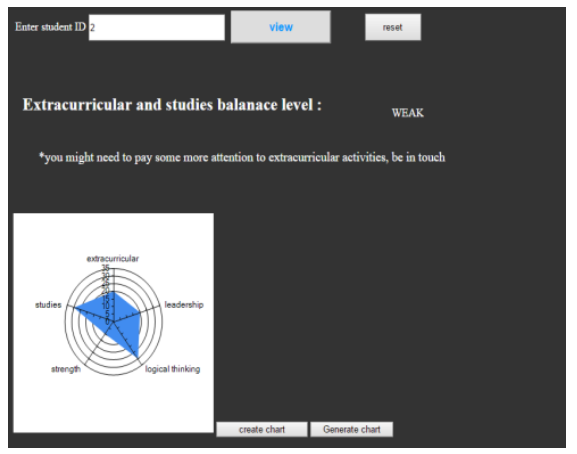

Figure 3. Performance output

As shown in figure 3, when the user enters the Student ID and click on view button the system will display the correlation between studies and extracurricular activities of that student. Once the user clicks on Create chart button a Radar chart will be displayed showing the performance of the student.

The accuracy of the 'Sisu Manthalawa' System varies according to the amount of data used for data mining. The current system retains an approximate accuracy level of $69 \%$. Lack of data of previous results of the students have caused the rest of the accuracy points. The accuracy may increase as more data are added to be mined.

\section{CONCLUSION}

Students and teachers are the targeted users of this research. Considering about students, much of them have no idea on how to identify the correct path, their strengths, weaknesses and correct academic grouping for studies. Through the implemented system, students who failed to identify what they are talented in and who they have to group up with, will be able to identify their weaknesses by themselves. The intention of developing the Sisu Manthalawa is to allow students to understand what their real talents and standards, thus helping them to choose a path that leads to a brighter future career.

There are some limitations to be highlighted in "Sisu Manthalawa" system. In order to use the system a student must have an average English knowledge and Information Technology knowledge .Though IT knowledge is a limitation, IT knowledge is not very poor among present day student population. Since this is a web application, it is necessary to have a good internet connection. This system is created based on Sri Lankan education system, hence this application cannot be applied to any other external education systems.

Recommendations to those who are willing to develop this system further are as follows:

- A time table for each and every individual student

- Add games to practice academic subjects

- Develop the system to support mobile devices with new or improved algorithm.

- A communication method to send information to the parents who are willing to know about their child's overall performance.

As the research was limited to a specific time period the research group was able to focus on only a limited amount of components. In the future the group is willing to do more researches and develop a method for the web application to measure a student's psychological characteristics. Also a data mining algorithm can be used to decide the possibility of a student passing a particular subject. Moreover, the system can be built to process using an Artificial Intelligence.

\section{ACKNOWLEDGMENT}

The research team take this opportunity to sincerely acknowledge the individuals and groups who have provided guidance and assistance throughout the project,

First and foremost we would like to thank Dr. Yasas Jayaweera and rest of the Academic and non-Academic staff of the SLIIT.

We would also like to thank the staff of both schools $\mathrm{Ch} /$ Dhammissara National College Nattandiya, Nik/Sri Sumangala National College, Wariyapola.

We thank Dr. Jayamal De Silva, Senior Lecturer in Psychiatry of University of Sri Jayawardanapura and Consultant Psychiatrist of Colombo South Teaching Hospital, Kalubowila and the other Staff members of the Hospital who provided help and materials.

Finally we would like to acknowledge with gratitude, the support provided by others whose names were not mentioned.

\section{REFERENCES}

[1] M. Gogaa, S. Kuyorob and N. Gogaa, "A Recommender for Improving the Student Academic Performance", Sciencedirect.com, 2014. [Online]. Available:http://www.sciencedirect.com/science/articl e/pii/S1877042815016420. [Accessed: 15- Feb2016].

[2] B. Oakley, D. Hanna, Z. Kuzmyn and R. Felder, "Best Practices Involving Teamwork in the Classroom: Results From a Survey of 6435 Engineering Student Respondents", IEEE Trans. Educ., vol. 50, no. 3, pp. 266-272, 2007.

[3] C. Romero, S. Ventura, P. Espejo and C. Hervás, "Data mining algorithms to classify students",Academia.edu, 2008. [Online]. Available:http://www.academia.edu/2662260/Data_m ining_algorithms_to_classify_students. [Accessed: 15- Feb- 2016]. 
[4] G. Zurita, M. Nussbaum and R. Salinas, "Dynamic Grouping in Collaborative Learning Supported by Wireless Handhelds." Educational Technology \& Society, vol. 8, no. 3, pp. 149-161, 2005.

[5] J. Moriana, F. Alos, R. Alcala, M. Pino, J. Herruzo and R. Ruiz, "Extra-Curricular Activities and Academic Performance in Secondary Students.", Electronic Journal of Research in Educational Psychology, vol. 4, no. 1, pp. 35-46, 2006.

[6] M. Murphy, R. Seneviratne, L. Cochrane, M. Davis and G. Mires, "Impact of student choice on academic performance: cross-sectional and longitudinal observations of a student cohort", BMC Medical Education, vol. 13, no. 1, p. 26, 2013.

[7] J. Cubillo, J. Sánchez and J. Cerviño, "International students' decision_making process: International Journal of Educational Management: Vol 20, No 2", International Journal of Educational Management, 2006.

[8] A. Singh, L. Uijtdewilligen, J. Twisk, W. Mechelen and M. Chinapaw, "Physical Activity and Performance at School", Arch Pediatr Adolesc Med, vol. 166, no. 1, p. 49, 2012.

[9] M. Richardson, C. Abraham and R. Bond, "Psychological correlates of university students' academic performance: A systematic review and meta-analysis.", Psychological Bulletin, vol. 138, no. 2, pp. 353387, 2012.

[10] V. Vanno, W. Kaemkate and S. Wongwanich, "Relationships between Academic Performance,Perceived Group Psychological Capital, and Positive Psychological Capital of Thai
Undergraduate Students", Sciencedirect.com, 2014. [Online].

Available: http://www.sciencedirect.com/science/article/pii/S187 7042814007563. [Accessed: 15- Feb- 2016].

[11] J. Wang and J. Shiveley, "The Impact of Extracurricular Activity on Student Academic Performance", 2009. [Online].

Available:

http://www.csus.edu/oir/Research\%20Projects/Studen t\%20Activity\%20Report\%202009.pdf. [Accessed: 15- Feb- 2016].

[12] R. Zeitun, K. Abdulqader and A. Khaled, "Team Satisfaction and Student Group Performance: A Cross-Cultural Study", Journal of Education for Business, 2013.

[13] N. Rania, S. Rebora and L. Migliorini, "Team-based Learning: Enhancing Academic Performance of Psychology Students", Sciencedirect.com, 2015. [Online]. Available: http://www.sciencedirect.com/science/article/pii/S187 7042815007685. [Accessed: 15- Feb- 2016].

[14] P. Cortez and A. Silva, "Using data mining to predict secondary school student performance", EUROSIS 2008. [Online]. Available: http://repositorium.sdum.uminho.pt/handle/1822/8024 . [Accessed: 15- Feb- 2016].

[15] Macaskill, A. (2013). The mental health of university students in the United Kingdom. British Journal of Guidance \& Counselling, 41(4), pp.426-441.

[16] Hinderaker, D. (2012). College Student Mental Health and Use of OnCampus Counseling Center Services. MSW Clinical Research Paper. 